\title{
Landslide early warning based on failure forecast models: the example of the Mt. de La Saxe rockslide, northern Italy
}

\author{
A. Manconi ${ }^{1, \mathrm{a}}$ and D. Giordan ${ }^{1}$ \\ ${ }^{1}$ Geohazard Monitoring Group, CNR IRPI, Strada delle Cacce 73, 10135 Turin, Italy \\ ${ }^{a}$ now at: Swiss Federal Institute of Technology, Department of Earth Sciences, Zurich, Switzerland
}

Correspondence to: A. Manconi (andrea.manconi@irpi.cnr.it)

Received: 30 January 2015 - Published in Nat. Hazards Earth Syst. Sci. Discuss.: 23 February 2015

Accepted: 10 July 2015 - Published: 29 July 2015

\begin{abstract}
We apply failure forecast models by exploiting near-real-time monitoring data for the La Saxe rockslide, a large unstable slope threatening Aosta Valley in northern Italy. Starting from the inverse velocity theory, we analyze landslide surface displacements automatically and in near real time on different temporal windows and apply straightforward statistical methods to obtain confidence intervals on the estimated time of failure. Here, we present the result obtained for the La Saxe rockslide, a large unstable slope located in Aosta Valley, northern Italy. Based on this case study, we identify operational thresholds that are established on the reliability of the forecast models. Our approach is aimed at supporting the management of early warning systems in the most critical phases of the landslide emergency.
\end{abstract}

\section{Introduction}

The use of analytical and numerical models to determine the occurrence of natural hazards is a major research subject. For landslides, this topic not only has great relevance in the scientific community but also strongly affects best practices for efficient land planning and management. The approaches used to forecast landslide occurrence mainly depend on the spatial scale analyzed (regional vs. local) and the temporal range of forecast (long term vs. short term), as well as the triggering factor and the landslide type being considered. A certain proportion of landslides are triggered by intense and prolonged rainfall events; thus, a large number of studies have focused on the relationship between intensity/duration of rainfall and the consequent activation (or re-activation) of landslides (Wieczorek and Guzzetti, 1999). In general, the main inputs for these analyses are retrieved from rain gauge data and historical landslide catalogs. Models are used to identify and calibrate the intensity and duration thresholds that, if exceeded during a rainfall event, indicate the likely occurrence of landslides in a specific area with a specified degree of uncertainty. Early warning systems (EWSs) based on this approach rely on the acquisition of near-real-time data from rain gauges and consider both measured precipitation and rain forecasts based on meteorological models (Rossi et al., 2012). EWSs of this type are used worldwide and are usually applied at regional scales; they constitute a suitable solution in areas where the combination of climatic conditions, landslide susceptibility, and dense population generates highrisk exposure.

By considering large slope instabilities, event forecasting may be approached in a different manner. Large unstable slopes display a wide range of failure behaviors, from slow slope deformations to rapid and catastrophic rockslides. One of the most critical issues related to these phenomena is their likelihood of evolving into impulsive gravitational events involving some or all of the unstable mass (e.g., rockfalls and/or rock avalanches). In this context, surface displacements and/or deep-seated deformation often represent the key information for a proper understanding and interpretation of the phenomenon (Wieczorek and Snyder, 2009).

When unstable slopes menace populations and/or important infrastructure, monitoring networks are set up as the basis of EWSs. In such situations, EWSs may rely on thresholds defined with respect to direct measurements of physical parameters describing the landslide evolution over time, i.e., surface and/or sub-surface displacement data (Michoud et al., 2013). If thresholds are exceeded, specific actions are 
typically prescribed to reduce the consequences of a potential landslide failure on the population and/or exposed infrastructure (Medina-Cetina and Nadim, 2008). The identification of thresholds for rockslide displacements (or velocities) is generally approached by performing back analyses on the available monitoring data and/or considering similarities to previous case studies in terms of geology and volume of the material involved. However, this is not always possible. Problems with the identification of these thresholds are well known, mainly resulting from the complexity of the phenomena analyzed, as well as from the large number of variables involved (Crosta and Agliardi, 2002). Moreover, an additional limitation of this approach is that the efficacy of EWSs is lost when the last threshold is exceeded. Once this condition is reached, the time before a slope failure produces a (partial or total) landslide occurrence is still unknown, and thus the critical situation can be protracted for long periods. This is usually the most critical stage of the landslide emergency.

In the last decades, several modeling procedures have been proposed for the estimation of the time of failure (ToF) for landslide phenomena. These approaches, hereafter referred to as failure forecast methods (FFMs), analyze the evolution of the landslide deformation over time (i.e., the strain rate) and are based on the assumption that under constant stress conditions, landslide materials follow the creep mechanism. After the pioneering work of Saito (1965), a number of authors have attempted to estimate ToF using different approaches, including simplified empirical and/or graphical solutions, analytical models known as "regression-only" methods, and physically consistent methods (see Federico et al., 2012, and references therein). The "inverse-velocity" method proposed by Fukuzono (1985) has been widely considered and has led to successful applications both in largescale laboratory experiments and in real landslide scenarios (Dick et al., 2015; Mazzanti et al., 2015; Rose and Hungr, 2007). This approach exploits the evolution over time of the inverse value of the surface velocity $(v)$ by assuming that failure approaches as $v^{-1}$ tends to zero.

Recently, starting from Fukuzono's method, Manconi and Giordan (2014) proposed a new approach to achieve landslide ToF forecast by considering near-real-time monitoring data. While in Manconi and Giordan (2014) we presented the details on the failure forecast modeling approach, in this paper we aim to define operative thresholds based on the results of the failure forecast models. Our goal is to contribute to filling an important gap, i.e., supporting authorities and decision makers during the time frame between the point when thresholds set on displacements (or its derivatives) are exceeded and the occurrence of a (partial or total) landslide failure.

\section{Failure forecast in near real time}

Let us assume that an active monitoring network is deployed on the landslide area and that the information on the defor-

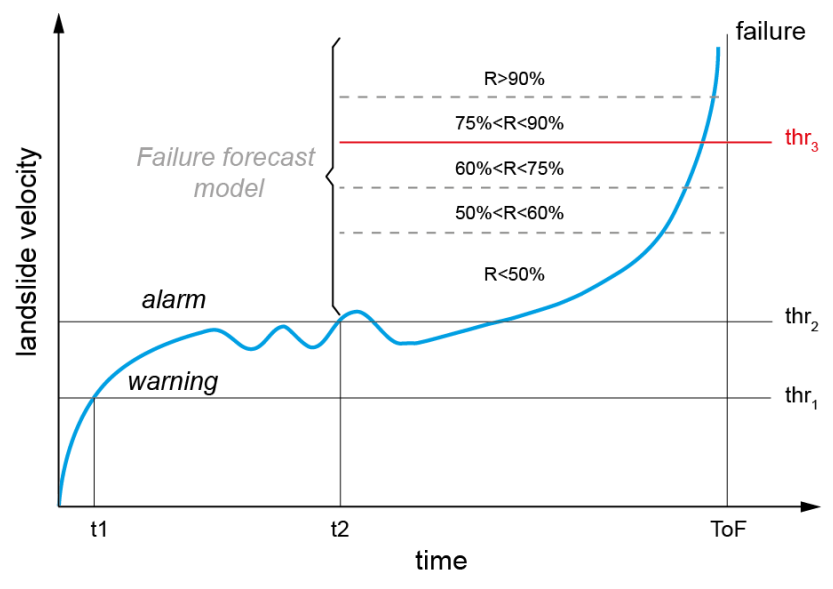

Figure 1. Schematic representation of the evolution over time of landslide velocity prior to a failure event, by considering materials behaving under creep conditions. The evolution towards failure may have different phases characterized by non-linear accelerations. While thr ${ }_{1}$ and $t_{2} r_{2}$ are static thresholds defined from a priori information on the landslide behavior, $\mathrm{thr}_{3}$ is based on the results from the failure forecast modeling obtained in near real time.

mation field is delivered in near real time. Figure 1 depicts an example of the temporal evolution that might be observed in landslide surface velocity prior to failure occurrence. Under these conditions, the monitoring network is usually coupled to an EWS based on three stages associated with two predefined velocity $(v)$ thresholds: (i) $v<\operatorname{thr}_{1}=$ landslide velocity is below values considered critical; (ii) $v>\operatorname{thr}_{1}=$ warning conditions; (iii) $v>\mathrm{thr}_{2}=$ alarm. When $\mathrm{thr}_{1}$ or thr $\mathrm{t}_{2}$ are exceeded at a specific measurement point (or area), the EWS can be set to send alert messages (e.g., via SMS and/or email) to the responsible authorities. The latter must evaluate the situation and eventually activate specific civil protection procedures (Allasia et al., 2013; Intrieri et al., 2012). An EWS using thresholds based only on the actual measured deformation values does not provide any information about the possible evolution of the landslide towards failure. Indeed, the time between the passing of $\mathrm{thr}_{2}$ to the slope failure is unknown, posing serious concerns for the management of emergency scenarios. For example, if the civil protection procedures associated with the stage " $v>\operatorname{thr}_{2}$ " are "evacuation of inhabited buildings" or "closure of the access roads", the main question of decision makers under these conditions is "how long should we keep buildings empty and/or roads closed?". In several scenarios, due to the high variability of landslide behavior, uncertainty over which protection procedures to adopt can last for several days or even weeks, causing discomfort to the population and economic loss. Adoption of failure forecast models during this critical phase could mitigate these problems. More specifically, here we apply Fukuzono's inverse-velocity method by considering several calculation time windows (CTWs, data acquired over the last $12 \mathrm{~h}, 24 \mathrm{~h}, 48 \mathrm{~h}, 1$ week, etc.) and iter- 
ate the procedure several times (e.g., $N=1000$ iterations) within a bootstrap resampling strategy (readers are referred to Manconi and Giordan, 2014, for more detail). This approach is aimed at evaluating the evolution of landslide status by considering data over different periods, as well as deriving robust assessments of errors associated with the ToF estimate. In addition, the fit of the forecast to the observations is evaluated by calculating Pearson's correlation coefficient (CC) between the model and the data. Normalized CC values, when statistically significant, can be interpreted as a measure of the reliability $(R)$ of the computed forecast model. At this stage, we consider a number of $R$ ranges, as follows: (i) $50 \%<R<60 \%=$ model reliability is low, failure is unlikely but the situation must be surveyed; (ii) $60 \%<R<75 \%=$ model reliability is higher, a failure within the estimated ToF range starts to be more likely; (iii) $75 \%<R<90 \%=$ model reliability is high, a failure within the estimated ToF range is likely; (iv) $R>90 \%=$ model reliability is very high, a failure within the estimated ToF range is highly probable. In general, the results of the failure forecast procedure presented herein must be read as follows: if the landslide velocity continues to increase as in the last CTW, the probability of observing a failure within the estimated ToF range is $R \%$.

Additional information to take into account when interpreting the FFM results is the consistency of the forecast among different CTWs as well as the evolution tendency of $R$. For example, if $R$ progressively increases and/or remains stable over high values (e.g., $R>75 \%$ ), the probability of observing a failure is higher.

To facilitate the exploitation of this information based on failure forecasting as well as to provide a straightforward understanding of the modeling results to people without detailed knowledge of the inverse-velocity theory, we designed specific representations aimed at summarizing the obtained results (see Fig. 2). We have implemented this procedure within the ADVICE system (Allasia et al., 2013), and failure forecast plots are generated automatically when monitored target velocities exceed $v>\mathrm{thr}_{2}$.

\section{Application to Mont de La Saxe rockslide}

Active mass movement affects a large portion of the southern flank of the Mont de la Saxe, in the northwestern part of Aosta Valley, northern Italy. The rockslide, hereafter referred to as La Saxe, involves an unstable volume of ca. $8 \times 10^{6} \mathrm{~m}^{3}$ (Crosta et al., 2014, 2015) and poses a hazard to part of the Courmayeur municipality, i.e., Entreves and La Palud villages. In addition, the landslide threatens a crucial point of route E25, an important highway connection crossing Europe from north to south and ensuring commercial activities between Italy and transalpine countries. Continuous monitoring of surface displacements started in 2009 and showed that spring snowmelt causes progressive acceleration of the

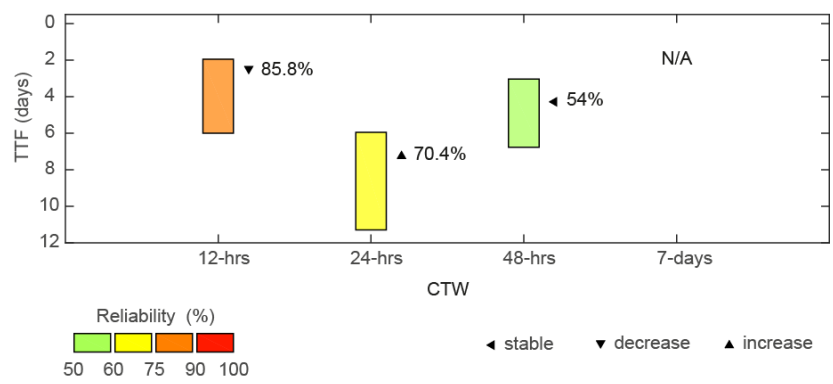

Figure 2. Example of the failure forecast plots. The $x$ axis represents the different computational time windows (CTWs), while the $y$ axis indicates the predicted time to failure (TTF $=$ ToF-now, where now is the time of the current computation). The bar length is a function of the TTF range between 5 and 95 percentiles computed with the bootstrap procedure (see text for details). The bar colors depend on the forecast model reliability values $(R)$. Black triangles indicate the reliability tendency with respect to the previous model: an increase (or decrease) occurs when current $R$ is higher (or lower) by $1 \%$. N/A indicates that the modeling results are not reliable; thus the failure forecast model is not applicable.

surface displacements, which may locally reach up to several decimeters or even meters per day. Over the years, these acceleration phases have led to failures of portions of the landslide body, with volumes ranging from minor rockfalls up to relatively larger mass wasting $\left(>1 \times 10^{4} \mathrm{~m}^{3}\right)$. The monitoring network deployed includes several instruments to measure surface displacements (Crosta et al., 2014), as follows: (i) a robotized total station (RTS) measuring every hour the 3-D position of approximately 30 optical targets installed on the landslide body; (ii) a ground-based synthetic aperture radar (GB-SAR), measuring at time intervals ranging from a few minutes to approximately $1 \mathrm{~h}$, adapted depending on the current landslide velocity; (iii) 8 continuous GPS receivers, also installed on the landslide body. However, the EWS thresholds are based mainly on measurements performed via the RTS. When one or more RTS point targets overcome predefined warning and/or alarm levels ( 1 and $2 \mathrm{~mm} \mathrm{~h}^{-1}$, respectively, considered over a $24 \mathrm{~h}$ observation window), specific civil protection procedures are activated, including the interruption of road traffic and evacuation of inhabitants from edifices located in areas potentially involved in a failure event.

Starting at the end of March 2014, a specific sector of the La Saxe rockslide started to accelerate (see Fig. 3), with surface velocities reaching values up to $5-6 \mathrm{~cm}$ per day. This acceleration phase has caused a large number of minor rockfalls as well as two main failure events: (i) 17 April 2014, 20:00 CET, ca. $5 \times 10^{3} \mathrm{~m}^{3}$ and (ii) 21 April 2014, 23:00 CET, ca. $3 \times 10^{4} \mathrm{~m}^{3}$. Figure 4 shows examples of the failure forecast plots generated in near real time from RTS measurements on target B4 during this particular phase. Target B4 was installed close to the zone characterized by the largest displacements and at that moment was considered to be one 


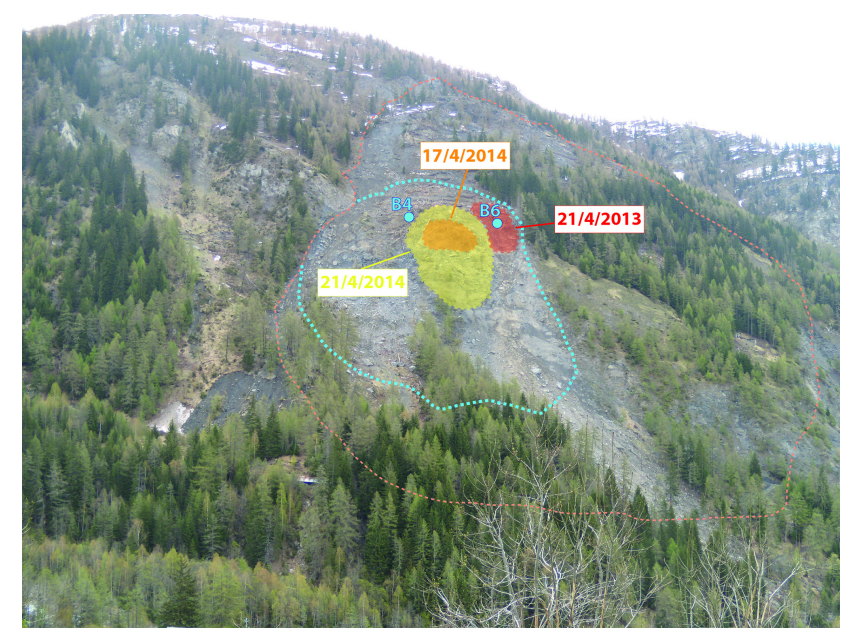

Figure 3. Frontal view of the La Saxe rockslide (April 2013). Red dashed line is the limit of the unstable slope, while blue dashed line defines the most active landslide sector. B4 and B6 are the location of the RTS targets considered for the failure forecast. Colored areas represent the zones collapsed on 21 April 2013 (reddish), 17 April 2014 (orange), and 21 April 2014 (yellow), respectively.

of the most representative for understanding the evolution of this kinematic domain. We noticed that from 31 March to 15 April, the reliability of the FFM progressively increased for all the CTWs considered. At this stage, landslide material had reached surface displacement rates larger than several centimeters per hour, and a failure was considered highly probable.

\section{Discussion and conclusions}

We presented an approach aimed at updating operational EWS thresholds by including values based on the results of the failure forecast method. Our approach has been applied to forecast landslide events associated with the evolution of the La Saxe rockslide during the 2014 emergency scenario. The results show that reliability thresholds applied to FFM results can be used to help the interpretation of the evolution of the landslide body towards a failure and to provide additional support for early warning purposes. Despite the limited number of events observed so far, we evaluated the performance of the proposed methodology by building contingency tables (Jolliffe and Stephenson, 2012). For this purpose, we have taken into account the failure forecast results for the La Saxe failure event of 21 April 2013 (see Manconi and Giordan, 2014) and the two major events that occurred in 2014. In particular, the analysis was performed by using for "event forecasting" only those models with reliability $(R)$ higher than a predefined value. Among them, models predicting a ToF range that included the time of the real events observed have been considered to be "true positive", while "false alarms" are models predicting a ToF range earlier than the real event occurrence, and "missed alarms" are models predicting a ToF range later than the real event occurrence. Models with $R$ below the predefined reliability threshold have been considered to be "non-event forecasts" and thus as true negatives. The analysis was performed on forecast models producing reliability thresholds $R>75 \%$ and $R>90 \%$ in the week preceding the failure (see Supplement). We note that the model hit rate for the 2013 event is on the order of 0.8 (see Table S7) and depends highly on the computational time windows considered. However, the modeling procedure yields a consistent number of false alarms, although among these, the mean distance between the predicted and the real event is on the order of 2.5-3 days. Moreover, we note that by considering only the forecast models with $R>90 \%$, the number of missed alarms approaches zero. For the 2014 events, the evaluation of the model performance with standard contingency estimators is difficult to interpret. The event of 21 April 2013 occurred after a straightforward evolution towards failure, and the target analyzed was installed right on top of the collapsed landslide sector (see Fig. 3). By contrast, the 2014 emergency scenario was characterized by a different evolution. In particular, in the period from 15 to 21 April 2014, a progressively increasing number of rockfalls and minor collapses were observed (Bertolo and Arrighetti, 2014), and the landslide acceleration was highly non-linear. In addition, while the landslide acceleration trend was recorded by several RTS targets, none of them was located right on the sectors that finally collapsed (see Fig. 3). This is a main limitation of using this type of failure forecast model on point data: if the point is not representative of the collapsing sector, the forecasted time of failure can be inaccurate. Under these conditions, the use of time series retrieved from GB-SAR, which provide a spatially distributed map of surface displacements, can be helpful; however, in this specific case, SAR data accuracy suffered from the occurrence of very large and/or rapid deformation, hindering its measuring capabilities due to signal decorrelation (see Casu et al., 2011).

For the above-discussed reasons, it is difficult to identify proper failure events for cases like those encountered during the La Saxe 2014 emergency phase. In these specific cases, instead of failure events it is more appropriate to define a "critical time range" when failure may occur. Based on the modeling results obtained for the La Saxe case study, we can consider $\mathrm{thr}_{3}=R>75 \%$ to be a good compromise to catch in advance the occurrence of the critical time range (see Fig. 1). We emphasize that, as for forecast models relevant to other natural phenomena (e.g., meteorological events), our results are based on statistical inference and must always be considered in terms of probability. Moreover, unpredictable changes of the boundary conditions, as well as deviations in the material behavior from the classical creep theory, may deeply affect the results of the forecast model (Mazzanti et al., 2015).

The main advantage of the method presented herein is that additional thresholds are based on the results of failure fore- 

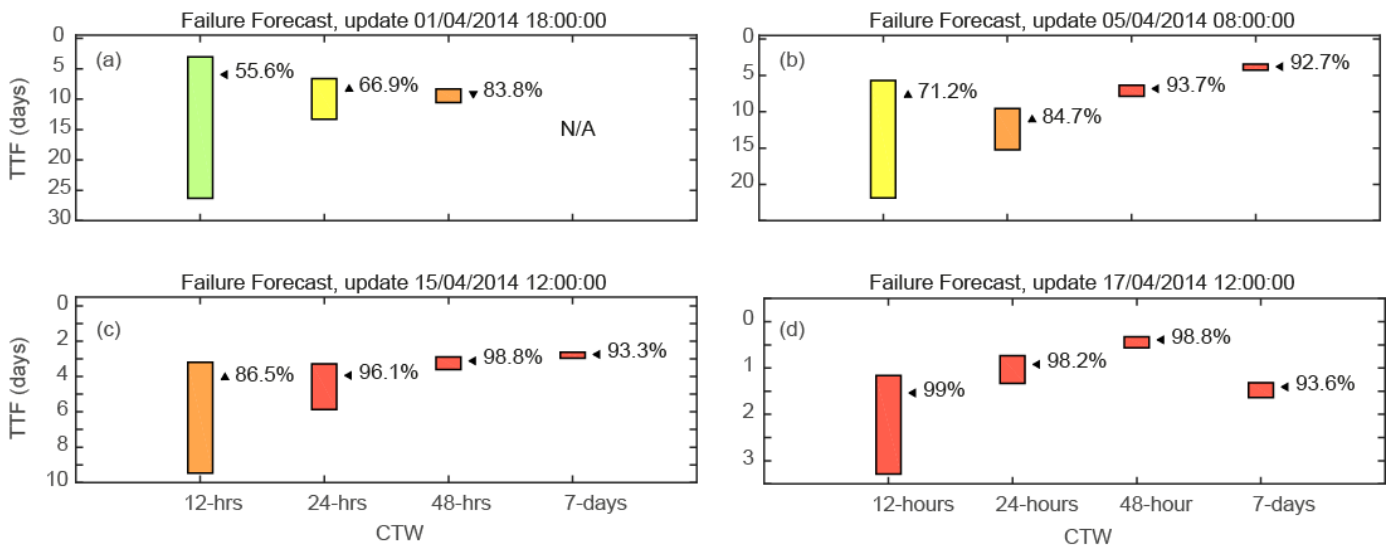

Figure 4. Results of the failure forecast procedure obtained in near real time during the 2014 emergency scenario. Note how the TTF predicted varies depending on the CTW considered.

cast models computed in near real time and thus rely only on the status of the landslide as defined by the measurements currently available, requiring neither a calibration period nor back analyses. It is worth mentioning that our method has been developed to achieve reliable short-term failure forecasts and is not intended for medium- and long-term predictions of the ToF. On the contrary, we aim to provide a supporting toolbox to manage EWSs in critical situations, especially when predefined early warning thresholds are exceeded. EWS managers can benefit from the additional information provided by the FFM because when the reliability of the forecast is high and a landslide failure thus more likely, authorities can be informed in advance (in an automatic and/or semi-automatic manner) and thus have the time to take countermeasures. The final interpretation of landslide failure potential must be provided by experienced users who have a deep knowledge of landslide phenomena, have access to additional data on landslide status, and are conscious of the limitations of FFM. Thus, the FFM information can be better interpreted by taking carefully into account additional evidence from other data sources, depending on the specific context. Further investigation on the reliability and accuracy of the method presented herein will be performed, mainly by considering different data sources as well as performing tests on a larger number of case studies.

\section{The Supplement related to this article is available online at doi:10.5194/nhess-15-1639-2015-supplement.}

Acknowledgements. We thank D. Bertolo of Geological Survey of the Aosta Valley region, for the data availability and for fruitful discussions. The comments provided by two anonymous reviewers and by the editor F. Catani helped to improve the manuscript.

Edited by: F. Catani

Reviewed by: two anonymous referees

\section{References}

Allasia, P., Manconi, A., Giordan, D., Baldo, M., and Lollino, G.: ADVICE: A New Approach for Near-Real-Time Monitoring of Surface Displacements in Landslide Hazard Scenarios, Sensors, 13, 8285-8302, doi:10.3390/s130708285, 2013.

Bertolo, D. and Arrighetti, S.: Early detection of rockfalls and trajectory evaluation by "state-of-the art" computer vision technologies, in: Proceedings of the ROCEXS Meeting 2014, Lecco, Italy, 2014.

Casu, F., Manconi, A., Pepe, A., and Lanari, R.: Deformation Time-Series Generation in Areas Characterized by Large Displacement Dynamics: The SAR Amplitude Pixel-Offset SBAS Technique, IEEE T. Geosci. Remote, 49, 2752-2763, doi:10.1109/TGRS.2010.2104325, 2011.

Crosta, G. B. and Agliardi, F.: How to obtain alert velocity thresholds for large rockslides, Phys. Chem. Earth Pt. ABC, 27, 15571565, doi:10.1016/S1474-7065(02)00177-8, 2002.

Crosta, G. B., Prisco, C., Frattini, P., Frigerio, G., Castellanza, R., and Agliardi, F.: Chasing a complete understanding of the triggering mechanisms of a large rapidly evolving rockslide, Landslides, 11, 747-764, doi:10.1007/s10346-013-0433-1, 2014.

Crosta, G. B., Lollino, G., Frattini, P., Giordan, D., Tamburini, A., Rivolta, C., and Bertolo, D.: Rockslide Monitoring Through Multi-temporal LiDAR DEM and TLS Data Analysis, in: Engineering Geology for Society and Territory - Volume 2, edited by: Lollino, G., Giordan, D., Crosta, G., Corominas, J., Azzam, R., Wasowski, J., and Sciarra, N., Springer International Publishing, 613-617, 2015.

Dick, G. J., Eberhardt, E., Cabrejo-Liévano, A. G., Stead, D., and Rose, N. D.: Development of an early warning time-of-failure analysis methodology for open pit mine slopes utilizing groundbased slope stability radar monitoring data, Can. Geotech. J., 52, 515-529, doi:10.1139/cgj-2014-0028, 2015.

Federico, A., Popescu, M., Elia, G., Fidelibus, C., Internò, G., and Murianni, A.: Prediction of time to slope failure: a general framework, Environ. Earth Sci., 66, 245-256, doi:10.1007/s12665011-1231-5, 2012.

Fukuzono, T.: A New Method for Predicting the Failure Time of a Slope, University Press, Tokyo, 1985. 
Intrieri, E., Gigli, G., Mugnai, F., Fanti, R., and Casagli, N.: Design and implementation of a landslide early warning system, Eng. Geol., 147-148, 124-136, doi:10.1016/j.enggeo.2012.07.017, 2012.

Jolliffe, I. T. and Stephenson, D. B.: Forecast Verification: A Practitioner's Guide in Atmospheric Science, John Wiley \& Sons, Oxford, UK, 2012.

Manconi, A. and Giordan, D.: Landslide failure forecast in near-real-time, Geomat. Nat. Hazards Risk, doi:10.1080/19475705.2014.942388, in press, 2014.

Mazzanti, P., Bozzano, F., Cipriani, I., and Prestininzi, A.: New insights into the temporal prediction of landslides by a terrestrial SAR interferometry monitoring case study, Landslides, 12, 5568, doi:10.1007/s10346-014-0469-x, 2015.

Medina-Cetina, Z. and Nadim, F.: Stochastic design of an early warning system, Georisk Assess. Manage. Risk Eng. Syst. Geohaz., 2, 223-236, doi:10.1080/17499510802086777, 2008.

Michoud, C., Bazin, S., Blikra, L. H., Derron, M.-H., and Jaboyedoff, M.: Experiences from site-specific landslide early warning systems, Nat. Hazards Earth Syst. Sci., 13, 2659-2673, doi:10.5194/nhess-13-2659-2013, 2013.

Rose, N. D. and Hungr, O.: Forecasting potential rock slope failure in open pit mines using the inverse-velocity method, Int. J. Rock Mech. Min. Sci., 44, 308-320, doi:10.1016/j.ijrmms.2006.07.014, 2007.
Rossi, M., Peruccacci, S., Brunetti, M. T., Marchesini, I., Luciani, S., Ardizzone, F., Balducci, V., Bianchi, C., Cardinali, M., Fiorucci, F., Mondini, A. C., Reichenbach, P., Salvati, P., Santangelo, M., Bartolini, D., Gariano, S. L., Palladino, M., Vessia, G., Viero, A., Antronico, L., Borselli, L., Deganutti, A. M., Iovine, G., Luino, F., Parise, M., Polemio, M., Guzzetti, F., Luciani, S., and Tonelli, G.: "SANF: a national warning system for rainfall-induced landslides in Italy" in Landslides and Engineered Slopes: Protecting Society through Improved Understanding, Vol. 2, edited by: Eberhardt, E., Froese, C., Turner, K., and Leroueil, S., ISL NASL 2012, Banff, Alberta, Canada, 18951899, 2012.

Saito, M.: Forecasting the time of occurrence of a slope failure, vol. 11, Montreal, 537-541, 1965.

Wieczorek, G. F. and Guzzetti, F.: A review of rainfall thresholds for triggering landslides, in: Proc. of the EGS Plinius Conference, Maratea, Italy, 407-414, 1999.

Wieczorek, G. F. and Snyder, J. B.: Monitoring Slope Movements, in: Geological Monitoring, edited by: Young, R. and Norby, L., Geological Society of America, Boulder, Colorado, 245-271, 2009. 